\title{
DIAGNÓSTICO E TRATAMENTO ORTO-CIRÚRGICO DAS DEFORMIDADES DENTOFACIAIS CLASSE III
}

Felipe Bueno Rosetti BERNABÉ, Rafaela SCARIOT, Nelson Luis Barbosa REBELLATO, Delson João DA COSTA, Leandro Eduardo KLÜPPEL

As deformidades dentofaciais são alterações do desenvolvimento dos maxilares que freqüentemente resultam em desarmonias faciais e alterações da oclusão dentária. Para o tratamento desta condição, está bem estabelecido que os melhores resultados são obtidos quando existe a associação do tratamento ortodôntico à técnicas de cirurgia ortognática. A deformidade dentofacial associada a má-oclusão classe III ocorre em $2,5 \%$ da população, sendo que $40 \%$ desses casos são severos o suficiente para necessitar intervenção cirúrgica coadjuvante. Esta deformidade pode ser causada por excesso de crescimento mandibular (prognatismo mandibular) falta de crescimento maxilar (hipoplasia maxilar) ou a associação destas duas condições. Os objetivos do tratamento orto-cirúrgico são: obtenção de face harmônica; oclusão funcional; saúde das estruturas orofaciais e estabilidade do tratamento em longo prazo. Este trabalho tem como objetivo apresentar e discutir três casos clínicos de deformidade dentofacial classe III tratados no serviço de Cirurgia e Traumatologia BucoMaxilo-Facias da Universidade Federal do Paraná, enfatizando o diagnóstico e as opções de tratamento cirúrgico.

Palavras-chave: Cirurgia; Maloclusão; Prognatismo; Funcionalidade; Estética. 